Check for updates

Cite this: Chem. Commun., 2018, 54,5626

Received 20th March 2018, Accepted 8th May 2018

DOI: $10.1039 / c 8 c c 02227 e$

rsc.li/chemcomm

\section{EU-7 zeolite: a synthetic BIK type zeolite with high hydrothermal stability $\dagger$}

\author{
Michiel De Prins, (D) ${ }^{a}$ Elke Verheyen, ${ }^{a}$ Stef Kerkhofs, ${ }^{a b}$ Andreas Hoffmann, ${ }^{a}$ \\ Gina Vanbutsele, ${ }^{a}$ Sreeprasanth Pulinthanathu Sree, iD a Sambhu Radhakrishnan, (iD a \\ Leen Van Tendeloo, ${ }^{c}$ Eric Breynaert, (D) a Christine E. A. Kirschhock, (D) ${ }^{a}$ \\ Frank-Walter Schütze ${ }^{b}$ and Johan A. Martens iD *a
}

EU-7 zeolite with Si/Al ratio of 15 is identified as a BIK type zeolite. The framework charge is compensated with $\mathrm{Cs}^{+}$cations located in 8-ring channels at regular distances. Even partially exchanged, $\mathrm{Cu}$-loaded EU-7 is active in $\mathrm{NH}_{3}-\mathrm{SCR}$ and withstands hydrothermal aging at $900{ }^{\circ} \mathrm{C}$ needed for application in diesel particulate filters.

Small-pore zeolites with pore openings limited by 8 cornersharing tetrahedra such as the LTA type zeolite are frequently used in gas purification and separation, gas and solvent drying and water softening. They are also popular in catalysis, and especially for methanol-to-olefin conversion and selective catalytic reduction (SCR) of nitrogen oxides (NOx) with ammonia $\left(\mathrm{NH}_{3}\right)$ in exhaust gas aftertreatment systems. ${ }^{1-6}$ The reagents and products of the $\mathrm{NH}_{3}$-SCR reaction are small molecules, viz. $\mathrm{NO}, \mathrm{NO}_{2}, \mathrm{O}_{2}, \mathrm{H}_{2} \mathrm{O}, \mathrm{NH}_{3}, \mathrm{~N}_{2}$ which can access the intracrystalline pore volume of small-pore zeolites. The hydrothermal stability requirement for $\mathrm{NH}_{3}$-SCR catalysts is severe, especially when this catalytic function is to be integrated in the diesel particulate filter where the temperature during regeneration can reach up to $900{ }^{\circ} \mathrm{C}^{7,8}$ Many of the known small-pore zeolites are minerals and for several of them no synthetic counterpart exists. The growing interest in small-pore zeolites for catalysis justifies a search for synthetic versions of natural zeolites expected to have high hydrothermal stability. EU-7 zeolite was first reported by Araya and Lowe in $1986 .{ }^{9}$ According to Dewing et al. ${ }^{10}$ the zeolite was proposed to be related to EU-13, a 10-ring zeolite with MTT framework type ${ }^{11}$ and to EU-12 zeolite. ${ }^{12}$ Recently, the crystal structure of EU-12 was elucidated by synchrotron powder X-ray diffraction (XRD) and Rietveld analyses as a small-pore zeolite containing a 2-dimensional channel system consisting of 2 types of straight 8-ring channels intersected by a sinusoidal 8-ring channel. ${ }^{13}$ The topology of this framework has been assigned the

\footnotetext{
${ }^{a}$ Centre for Surface Chemistry and Catalysis, University of Leuven, Leuven, 3000, Belgium.E-mail: johan.martens@kuleuven.be

${ }^{b}$ Umicore AG\&Co. KG, Hanau, 63456, Germany

${ }^{c}$ Umicore AG\&Co. KG, Olen, 2250, Belgium

$\dagger$ Electronic supplementary information (ESI) available. See DOI: 10.1039/ c8cc02227e
}

3-letter code ETL by the structure commission of the International Zeolite Association in 2016. ${ }^{14}$ EU-7 zeolite can be synthesized in presence of Cs cations and butane-1,4-diamine as structure directing agent. ${ }^{9}$ Until now the structure of EU-7 zeolite remained elusive but now is identified as BIK type zeolite, a small-pore zeolite with a straight 1-dimensional channel system and high Si/Al ratio. Here we report the synthesis and structure analysis of EU-7 zeolite and an evaluation of its hydrothermal stability in view of $\mathrm{NH}_{3}-\mathrm{SCR}$ catalysis.

Synthesis of EU-7 zeolite was performed similar to example 7 of patent US4581212. ${ }^{9}$ More details on the synthesis and the characterization techniques can be found in the ESI. $\dagger$

The X-ray powder diffraction pattern of the EU-7 zeolite shown in Fig. 1 indicates the formation of crystalline material corresponding to the EU-7 zeolite reported in the original patent. ${ }^{9}$ SEM revealed the EU-7 zeolite to consist of a single phase and to form agglomerates from individual crystals having an ellipsoidal disk-like morphology with a size of around $4 \times 0.5 \mu \mathrm{m}$ (Fig. 2).

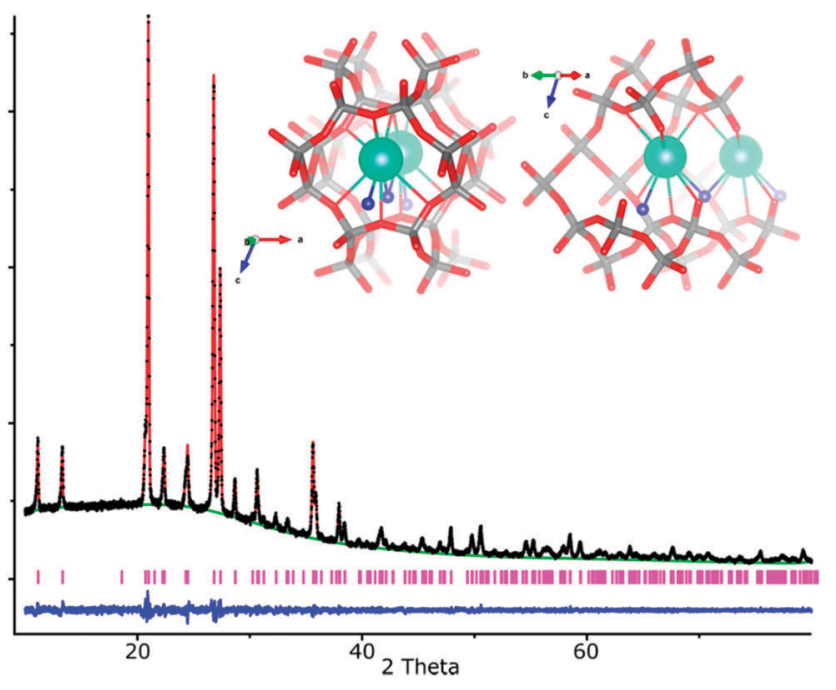

Fig. 1 Rietveld refinement of EU-7 zeolite. Location of Cs in the 8-membered ring channels is shown in the inset. 

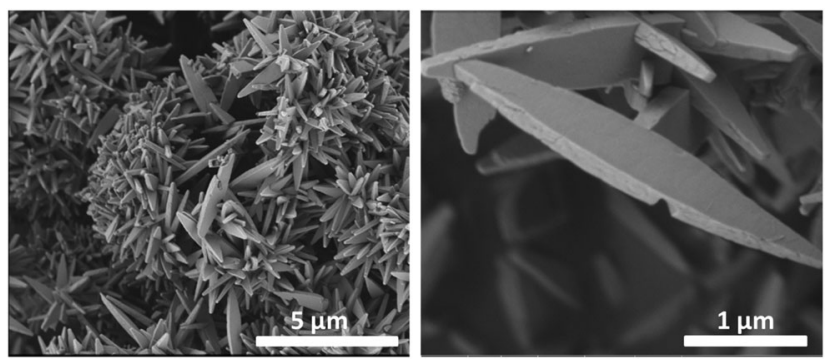

Fig. 2 HRSEM images of calcined EU-7 zeolite.

Indexing of the powder pattern (Fig. 1) indicated a monoclinic unit cell with lattice constants of $a=7.32 \AA, b=5.00 \AA$, and $c=17.49 \AA$ with a monoclinic angle of $114.75^{\circ}$. As most probable spacegroups $P 2_{1}, P \mathrm{c}$ and $P 2_{1} / c$ were identified. A structure determination by Monte-Carlo and parallel tempering using FOX ${ }^{15}$ in the spacegroup $P 2_{1} / c$ was attempted. Assuming a framework density similar to MTT and ETL zeolite, initially 4 independent tetrahedra next to 2 Cs positions were optimized, which quickly led to the conclusion the structure could be well described in $P 2_{1} / c$ using 3 crystallographic sites for tetrahedron sites plus one site for Cs. The 3D connected structure obtained was then optimized in terms of bond angles and distances by a forcefield simulations using the Gulp program and Catlow library. ${ }^{16,17}$ The obtained topology was analyzed with ToposPro, ${ }^{18}$ revealing the BIK topology. Rietveld refinement of the calcined sample stored at $60{ }^{\circ} \mathrm{C}$, with the GSAS software package, ${ }^{19,20}$ led to localization of 2 water molecule positions next to Cs and framework and to excellent reliability factors of $R_{\mathrm{p}}=2.6 \%$, $R_{\mathrm{wp}}=3.4 \%$ and $R_{\mathrm{F} 2}=8.3 \%$. Refinement of occupation factors of Cs also resulted in very good agreement with the experimental composition.

The BIK topology is named after the rarely occurring mineral bikitaite $\left(\mathrm{Li}^{2}\left[\mathrm{AlSi}_{2} \mathrm{O}_{6}\right] \cdot \mathrm{H}_{2} \mathrm{O}\right)$. Up to now, natural zeolites with BIK topology are found only in Zimbabwe and South Carolina, show a $\mathrm{Si} / \mathrm{Al}$ ratio of 2 and strictly contain $\mathrm{Li}$ cations for charge compensation. ${ }^{14,21}$ A synthetic zeolite with BIK framework type and composition $\mathrm{Cs}\left[\mathrm{AlSi}_{7.6} \mathrm{O}_{17.1}\right]$ has been reported by Annehed and Fälth. ${ }^{22}$ Later, Kato et al. synthesized zeolites with BIK framework type in mixed cation systems with molar gel compositions of $\mathrm{SiO}_{2}$ : 0.028-0.5 Al: 0.1-0.6 Cs: 0-0.26 M: $30 \mathrm{H}_{2} \mathrm{O}$ where $\mathrm{M}$ is $\mathrm{Li}$, Na or $\mathrm{K}^{23}$ It was observed the final products mainly contained Cs as counter ion and only traces of $\mathrm{Li}, \mathrm{Na}$, or K, respectively. Fig. 3 shows how the BIK topology consists of 5-, 6-, and 8-membered rings, forming straight 1D-channels delimited by $8 \mathrm{~T}$-atoms. The channels have small side pockets accessible through strongly squeezed 6-membered rings, alternating along the channel direction $(b)$.

When synthesized in purely inorganic systems the $\mathrm{Si} / \mathrm{Al}$ ratio was always found close to 7.5..$^{2,23}$ Chemical analysis of the present EU-7 zeolite indicated a Si/Al ratio of 15, while direct excitation ${ }^{27} \mathrm{Al}$ MAS NMR confirmed that $99 \%$ of the $\mathrm{Al}$ exists in tetrahedral co-ordination as expected for framework $\mathrm{Al}$ (see $\mathrm{ESI} \dagger$ for Experimental details). This is the highest reported Si/Al ratio for a BIK framework type zeolite, and can be related to the

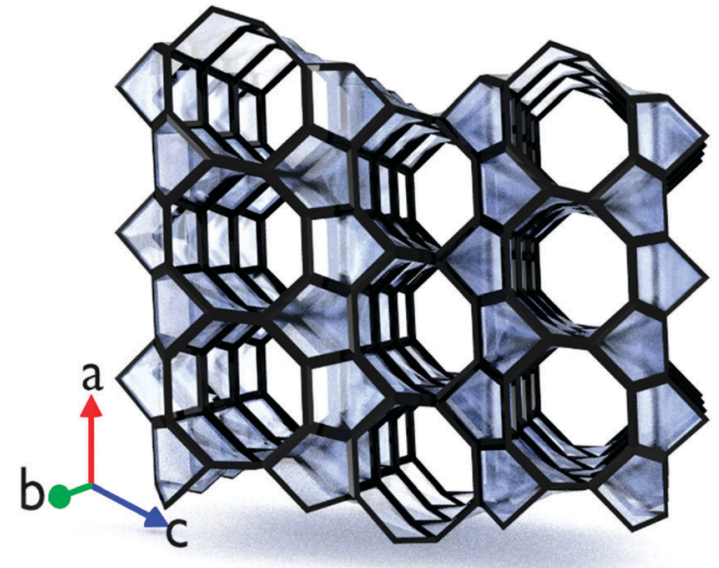

Fig. 3 Schematic representation of the BIK framework.

presence of diaminobutane during synthesis. The Cs-BIK obtained by purely inorganic synthesis by Annehed and Fälth ${ }^{22}$ was reported in spacegroup $B 2_{1}$, which after standardization results in a unit cell of $a=7.36 \AA, b=5.03 \AA, c=8.74 \AA$, with $\beta=114.12^{\circ}$ in spacegroup $P 2_{1}$. EU-7 zeolite shows a doubling of the unit cell in $c$-direction, but otherwise is very similar, also in position of the Cs-ion. In the present EU-7 zeolite 2 positions for water molecules were localized, which complete the coordination of the cations in the 8-membered ring channels. Cesium is coordinated by 6 framework oxygens plus 1 or 2 water molecules situated before and/or after the cation along the channel direction at distances between 3 and $3.5 \AA$. Owing to the high $\mathrm{Si} / \mathrm{Al}$ ratio only half of the cesium content compared to the previously reported material was expected. Indeed, per unit cell roughly 0.75 Cs ions are found in almost perfect agreement with the $\mathrm{Al}$ content (idealized zeolite formula $\left.\left|\mathrm{Cs}_{0.75}\right|\left[\mathrm{Si}_{11.25} \mathrm{Al}_{0.75} \mathrm{O}_{24}\right]\right)$. This also implies a high dispersion of the cations over the pore system so that directly neighboring Cs ions are not probable. This is in accordance with the observed doubling of the unit cell in $c$ direction, which may be caused by ordering of cation sites across neighboring channels. A detailed structural analysis exploring the possibility EU-7 zeolite may better be described in spacegroup $P C$ rather than $P 2_{1} / c$ is currently ongoing. The zeolite showed very small micropore volume according to $\mathrm{N}_{2}$ adsorption porosimetry, close to the detection limit of $c a .0 .01 \mathrm{~mL} \mathrm{~g}^{-1}$. Such low values are to be expected for a small pore zeolite with monodimensional pore system, in which Cs cations situated in the 8-membered rings are blocking passage to $\mathrm{N}_{2}$ molecules, especially at the temperature of $-196{ }^{\circ} \mathrm{C}$ of the recording of the $\mathrm{N}_{2}$ adsorption isotherm. Mobility of cations is expected at higher temperatures during $\mathrm{NH}_{3}$-SCR catalysis. Thermogravimetric analysis of as-synthesized sample showed a weight loss of 4 wt $\%$ between 30 and $200{ }^{\circ} \mathrm{C}$, assigned to $\mathrm{H}_{2} \mathrm{O}$. Above a temperature of $200{ }^{\circ} \mathrm{C}$, a low amount of weight loss was observed (0.4 wt\%), suggesting almost no incorporation of butane-1,4-diamine in the EU-7 zeolite. This is confirmed by the $\mathrm{Cs} / \mathrm{Al}$ atomic ratio of nearly 1 , as determined by Rietveld refinement. These extra-framework Cs cations are located in the one-dimensional 8-membered ring channels. This is confirmed 
by the lack of porosity of the calcined EU-7 zeolite as determined by nitrogen adsorption analysis. The large Cs cations are blocking access to the internal pore volume of the EU-7 zeolite. The high Si/Al ratio of the small-pore EU-7 zeolite makes this material potentially interesting for catalytic applications upon removal of the extra framework Cs cations to allow access to the internal pore volume of EU-7 zeolite. To remove Cs from the asmade material, the procedure described in example 11 of patent US4581212 was followed. Initially, a suspension of calcined EU-7 zeolite was equilibrated for $4 \mathrm{~h}$ in a stirred $0.5 \mathrm{M} \mathrm{NH} \mathrm{NH}_{4} \mathrm{Cl}$ solution (100 mL for $1 \mathrm{~g}$ of zeolite) under reflux conditions following recovery by centrifugation, the interstitial solution was removed by rinsing the sample with deionized water. This procedure was repeated twice. Afterwards, the sample was dried at $60{ }^{\circ} \mathrm{C}$ overnight. This treatment reduced the $\mathrm{Cs} / \mathrm{Al}$ ratio to 0.39 as compared to a ratio of 1 in the as made material. Following a drying step at $60{ }^{\circ} \mathrm{C}$, the sample was equilibrated for $2 \mathrm{~h}$ in a stirred $1 \mathrm{M} \mathrm{HCl}$ solution (100 $\mathrm{mL}$ for $1 \mathrm{~g}$ of zeolite) under reflux conditions. Subsequently, the solid phase was recovered by centrifugation, and rinsed with deionized water. This procedure was repeated 5 times. Finally, the zeolite was converted into the $\mathrm{NH}_{4}$ form by slurrying it in $\mathrm{NH}_{4} \mathrm{Cl}$ solution according to the first two steps in the procedure described above. Overall, the $\mathrm{Cs} / \mathrm{Al}$ ratio was reduced to 0.22 , corresponding to a Cs content $2.8 \mathrm{wt} \%$. X-ray diffraction showed the structure of the zeolite remained intact after both treatments. This reduction of the Cs content allowed to investigate the potential of EU-7 zeolite as small-pore $\mathrm{NH}_{3}$-SCR catalyst. Cs has a high affinity for the framework and is unlikely to exchange directly with the $\mathrm{Cu}$. The introduced $\mathrm{Cu}$ cations will exchange with the ammonium ions introduced in the post synthesis treatment. When more Cs is present, then also more pores and cation sites will remain inaccessible for the copper. $\mathrm{Cu}$ loaded samples were obtained by adding $2 \mathrm{~g}$ of Cs-depleted zeolite to a $200 \mathrm{~mL}$ aqueous solution containing $0.0189 \mathrm{~g}$ copper acetate monohydrate (Chem-Lab, 99+\%). This mixture was stirred for $20 \mathrm{~h}$ at room temperature. The zeolite was recovered by centrifugation and rinsed with deionized water. This procedure was repeated twice. Afterwards, the zeolite was dried at $60{ }^{\circ} \mathrm{C}$ overnight. This resulted in catalysts with a $\mathrm{Cu}$ loading of 0.18 and $0.19 \mathrm{wt} \%$ and idealized zeolite formula of $\left|\mathrm{Cs}_{0.39} \mathrm{Cu}_{0.03}\left(\mathrm{NH}_{4}\right)_{0.55}\right|\left[\mathrm{Al}_{0.75} \mathrm{Si}_{11.25} \mathrm{O}_{24}\right]$ and $\left|\mathrm{Cs}_{0.22} \mathrm{Cu}_{0.03}\left(\mathrm{NH}_{4}\right)_{0.72}\right| \quad\left[\mathrm{Al}_{0.75} \mathrm{Si}_{11.25} \mathrm{O}_{24}\right]$, respectively for the sample with and without $\mathrm{HCl}$ treatment. Despite this low amount, the $\mathrm{Cu}$ loaded EU-7 zeolite clearly shows $\mathrm{NH}_{3}$-SCR activity, as displayed in Fig. 4. Details on the $\mathrm{NH}_{3}$-SCR test and used set-up can be found in the ESI. $\dagger$

Both copper loaded EU-7 zeolite catalysts show activity at temperatures above $200{ }^{\circ} \mathrm{C}$. Between 200 and $300{ }^{\circ} \mathrm{C}$, the catalyst with $\mathrm{HCl}$ treatment has a better NO conversion, which might be ascribed to less Cs blocking the pores. Exposing the $\mathrm{Cu}$ loaded EU-7 zeolite to harsh hydrothermal conditions (12 vol\% $\mathrm{H}_{2} \mathrm{O}, 900{ }^{\circ} \mathrm{C}, 3 \mathrm{~h}$ as described in the ESI $\dagger$ ) reveals the extraordinary hydrothermal stability of EU-7 zeolite. The XRD patterns of the fresh and hydrothermally aged material, as well as the material after an $\mathrm{NH}_{3}$-SCR test, show no signs of structural collapse (Fig. 5). The high hydrothermal stability is

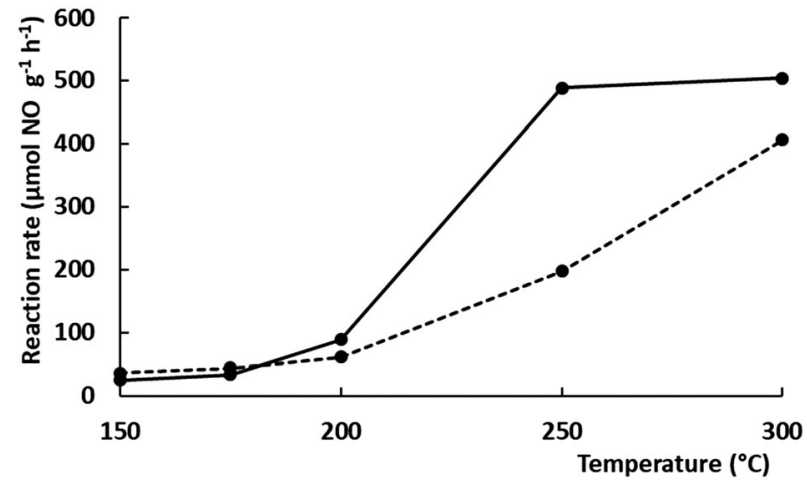

Fig. 4 Reaction rate as a function of temperature of the copper loaded EU-7 zeolite catalysts: sample with $0.19 \mathrm{wt} \% \mathrm{Cu}$ and $2.8 \mathrm{wt} \% \mathrm{Cs}$ (solid line) and $0.18 \mathrm{wt} \% \mathrm{Cu}$ and $5 \mathrm{wt} \% \mathrm{Cs}$ (dashed line). The feed consists of $500 \mathrm{ppm}$ $\mathrm{NO}, 450 \mathrm{ppm} \mathrm{NH}, 5 \% \mathrm{O}_{2}, 2 \% \mathrm{CO}_{2}, 2.2 \% \mathrm{H}_{2} \mathrm{O}$ balanced with $\mathrm{N}_{2}$ gas to obtain a total flow of $15 \mathrm{~L} \mathrm{~h}^{-1}$, resulting in a gas hourly space velocity of $30000 \mathrm{~h}^{-1}$

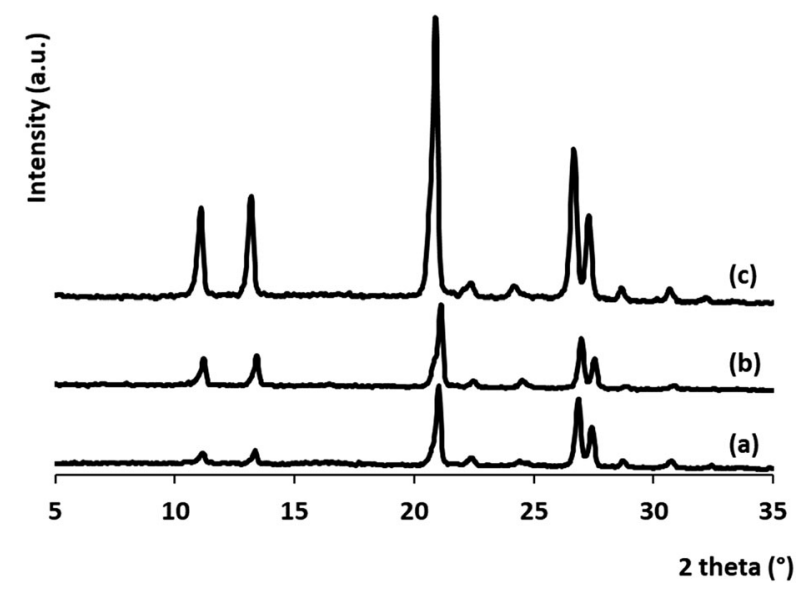

Fig. 5 X-ray diffraction pattern of (a) $\mathrm{Cu}$ loaded $\mathrm{EU}-7$ before reaction and hydrothermal aging: (b) after $\mathrm{NH}_{3}-\mathrm{SCR}$ reaction and (c) after hydrothermal aging.

necessary during regeneration of an SCR-coated diesel particulate filter. In literature, only 2 small-pore zeolites, i.e. AEI and LTA, have been reported to be stable up to $900{ }^{\circ} \mathrm{C}$ during a hydrothermal aging lasting at least 3 hours in the presence of at least $10 \%$ steam. $^{8,24}$ Of these materials, the aforementioned LTA has been synthesized using hydrogen fluoride, making the process difficult to implement on industrial scale. Cu-CHA, initially praised for its higher stability compared to Cu-loaded BEA and MFI (ZSM-5), ${ }^{25,26}$ remains stable up to $875{ }^{\circ} \mathrm{C}$ in the presence of steam. ${ }^{27}$ This study reveals BIK to be yet another robust zeolite withstanding high temperature hydrothermal aging.

In conclusion, the structure of EU-7 zeolite is revealed to correspond to a zeolite with a BIK framework type. The EU-7 zeolite in this work has the highest $\mathrm{Si} / \mathrm{Al}$ ratio reported up to now for any synthetic BIK. The material is exceptionally stable in hydrothermal conditions and showed no signs of structural collapse after a harsh $3 \mathrm{~h}$ treatment in 12 vol\% steam at $900{ }^{\circ} \mathrm{C}$. Only AEI and LTA have been known to survive a similar treatment. All currently available synthesis routes of BIK zeolites with 
high $\mathrm{Si} / \mathrm{Al}$ ratio require $\mathrm{Cs}$, which occupies the 8 -membered ring pores causing pore blocking. Though a large part of the Cs can be removed via ion exchange, including an intermediate acid treatment, residual Cs still effectively hinders access to the straight 8-membered ring channels. After ion exchange with copper, EU-7 zeolite proves to be an active $\mathrm{NH}_{3}$-SCR catalyst. The high hydrothermal stability combined with the catalytic activity makes the EU-7 zeolite a potential candidate for the next generation of $\mathrm{NH}_{3}$-SCR catalysts, provided the accessibility of the pore system can be further improved.

A. H. acknowledges VLAIO for a Baekeland research grant. J. A. M., C. E. A. K. and E. B. acknowledge the Flemish Government for long-term structural funding (Methusalem) and the Research Foundation Flanders (FWO) for financial support (1.5.061.18N, G083318N). NMR equipment was acquired with financial support by Hercules Foundation (AKUL/13/21), and by the Flemish Government, department EWI via the Hermes Fund (AH.2016.134).

\section{Conflicts of interest}

There are no conflicts to declare.

\section{Notes and references}

1 M. Moliner, C. Martínez and A. Corma, Chem. Mater., 2014, 26, 246-258.

2 U. Olsbye, S. Svelle, M. Bjrgen, P. Beato, T. V. W. Janssens, F. Joensen, S. Bordiga and K. P. Lillerud, Angew. Chem., Int. Ed., 2012, 51, 5810-5831.

3 S. I. Zones, US Pat., 4544538, 1985.

4 J. Wang, H. Zhao, G. Haller and Y. Li, Appl. Catal., B, 2017, 202, 346-354.
5 N. Martín, C. R. Boruntea, M. Moliner and A. Corma, Chem. Commun., 2015, 51, 11030-11033.

6 M. Moliner, C. Franch, E. Palomares, M. Grill and A. Corma, Chem. Commun., 2012, 48, 8264-8266.

7 A. Kawakami and T. Mizutani, SAE Tech. Pap. 2012-01-08 2012.

8 T. Ryu, N. H. Ahn, S. Seo, J. Cho, H. Kim, D. Jo, G. T. Park, P. S. Kim, C. H. Kim, E. L. Bruce, P. A. Wright, I. S. Namand and S. B. Hong, Angew. Chem., Int. Ed., 2017, 56, 3256-3260.

9 A. Araya and B. M. Lowe, Zeolite EU-7, US Pat., 4581212, 1986.

10 J. Dewing, M. S. Spencer and T. V. Whittam, Catal. Rev., 1985, 27, 61-514.

11 A. Araya and B. M. Lowe, Synthesis of Zeolite EU-13 from a Reaction Mixture Containing Tetramethylammonium Compound, US Pat., 4705674, 1987.

12 A. Araya and B. M. Lowe, Zeolite EU-12, US Pat., 4581211, 1986.

13 J. Bae, J. Cho, J. H. Lee, S. M. Seo and S. B. Hong, Angew. Chem., Int. Ed., 2016, 55, 7369-7373.

14 The International Zeolite Association Database of Zeolite Structures, http://www.iza-online.org, accessed September 2017.

15 V. Favre-Nicolin and R. Cerný, J. Appl. Crystallogr., 2002, 35, 734-743. 16 J. D. Gale, Z. Krist., 2005, 220, 552-554.

17 K. P. Schröder, J. Sauer, M. Leslie, C. Richard, A. Catlow and J. M. Thomas, Chem. Phys. Lett., 1992, 188, 320-325.

18 V. A. Blatov, A. P. Shevchenko and D. M. Proserpio, Cryst. Growth Des., 2014, 14, 3576-3586.

19 A. C. Larson and R. B. Von Dreele, Los Alamos Natl. Lab., 2000, 86-748.

20 B. H. Toby, J. Appl. Crystallogr., 2001, 34, 210-213.

21 E. John, W. Anthony, R. A. Bideaux, K. W. Bladh and M. C. Nichols, Handbook of Mineralogy, 2003.

22 H. Annehed and F. Lars, Z. Krist., 1984, 166, 301-306.

23 M. Kato, T. Ikeda and K. Tsutsumi, Microporous Mesoporous Mater., 2009, 117, 551-560.

24 T. Sonoda, T. Maruo, Y. Yamasaki, N. Tsunoji, Y. Takamitsu, M. Sadakane and T. Sano, J. Mater. Chem. A, 2015, 3, 857-865.

25 S. Shwan, R. Nedyalkova, J. Jansson, J. Korsgren, L. Olsson and M. Skoglundh, Ind. Eng. Chem. Res., 2012, 51, 12762-12772.

26 K. C. C. Kharas, H. J. Robota and D. J. Liu, Appl. Catal., B, 1993, 2, 225-237.

27 S. J. Schmieg, S. H. Oh, C. H. Kim, D. B. Brown, J. H. Lee, C. H. F. Peden and D. H. Kim, Catal. Today, 2012, 184, 252-261. 